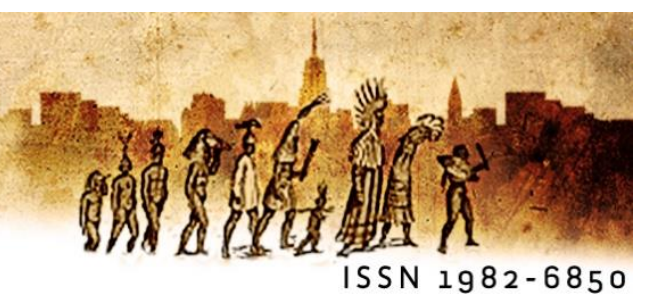

\title{
Um estudo sobre o pronome pessoal no pensamento de Saussure, Jakobson, Benveniste e Bello
}

Kelly Cristini Granzotto Werneri (UFSM)

\begin{abstract}
Resumo: Este estudo apresenta uma revisão bibliográfica sobre o pronome pessoal no pensamento de Saussure, Jakobson, Benveniste e Bello, buscando estabelecer relações de aproximação e distanciamento entre eles. Discute também a visão dos referidos autores e a apresentada pela gramática tradicional sobre o tema, especificamente a de língua castelhana. Conclui que as elaborações sobre o pronome de Jakobson, Benveniste e Bello dialogam entre si, distanciando-se de Saussure e da gramática espanhola tradicional.

Palavras-chave: Pronome; Pessoa; Enunciação; Gramática.

Resumen: Este estudio presenta una revisión bibliográfica acerca del pronombre personal en el pensamiento de Saussure, Jakobson, Benveniste y Bello, buscando establecer relaciones de aproximación y distanciamientos entre ellos. Discute también la visión de los referidos autores y la presentada por la gramática tradicional acerca del tema, específicamente la de lengua castellana. Concluye que las elaboraciones sobre el pronombre de Jakobson, Benveniste y Bello dialogan entre sí, alejándose de Saussure y de la gramática española tradicional.

Palabras claves: Pronombre; Persona; Enunciación; Gramática.
\end{abstract}

\section{Introdução}

Nos estudos linguísticos, a classe pronominal é tema de pesquisas e há diferenças no seu entendimento. Quando iniciamos no estudo de uma língua, seja ela materna ou estrangeira, as primeiras explicações sobre o referido grupo de palavras se dão pela gramática normativa ou pelo dicionário, na escola, ainda que o primeiro contato ocorra pelo uso, em determinadas situações comunicativas.

De acordo com a gramática normativa da língua espanhola, especificamente a da Real Academia Española (RAE), desde sua primeira edição (1771) até a última (2011), o 
pronome é apresentado como uma das nove classes de palavras ou partes da oração, reconhecidas pela instituição, a saber: nome, verbo, pronome, artigo, particípio, advérbio, preposição, conjunção e interjeição. É classificado em pronome pessoal, demonstrativo, possessivo e relativo. Nessa gramática ( $R A E, 1771$, p. 34, grifo do autor), "El PRONOMBRE es una palabra, o parte de la oración que se pone en lugar del nombre, como: yo en lugar de Pedro; tú en lugar de Antonio." ${ }^{\prime 1}$ Tal definição revela que o pronome é entendido como um elemento substitutivo.

Já o dicionário da Real Academia Española (DRAE) traz duas acepções para o pronome e, na sequência, suas classificações. Eis os dois verbetes:

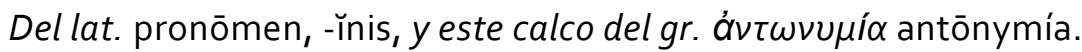

1. m. Gram. Clase de palabras cuyos elementos hacen las veces del sustantivo o del sintagma nominal y que se emplean para referirse a las personas, los animales o las cosas sin nombrarlos. Ella, esto, quién son pronombres.

2. m. Gram. Cada uno de los elementos que integran la clase pronombre 2 .

O dicionário apresenta o pronome como uma das classes de palavras, de um modo geral, e ainda como cada um dos tipos de pronomes de um modo particular, cuja função, às vezes, é ocupar o lugar do substantivo ou de um grupo nominal, ou seja, estar em seu lugar. Talvez essas conceituações e caracterizações do que é o pronome e suas funções sejam herança de visões clássicas sobre a classe pronominal, como a da gramática geral, de Arnauld e Lancelot (1660). Eles admitem a função substitutiva dos pronomes em relação aos nomes, justificando que isso evitaria a repetição. Os pronomes pessoais não escapam dessa função também, como afirma Lahud (1979, p.50):

Consequentemente, os pronomes pessoais, aparecem como simples substitutos "do nome daquele que fala" (primeira pessoa), "do nome daquele para quem se fala" (segunda pessoa) e "dos nomes das pessoas ou das coisas das quais se fala" (terceira pessoa), estando aqui englobados os demonstrativos, "que indicam como se fosse com o dedo a coisa de que se fala".

\footnotetext{
I"O PRONOME é uma palavra, ou parte da oração que se põe no lugar do nome, como: eu no lugar de Pedro; tu no lugar de Antonio." (tradução nossa).

${ }^{2}$ Do lat. pronōmen, -ĭnis, e este calco do gr. ávtwvupía antōnymía.

1. m. Gram. Classe de palavras cujos elementos fazem as vezes de substantivo ou do sintagma nominal e que se empregam para referir-se às pessoas, aos animais ou às coisas sem nomeá-los. Ela, isto, quem são pronomes.

2. m. Gram. Cada um dos elementos que integram a classe pronome. (tradução nossa).
} 
Percebemos, então, que as ideias de que os pronomes podem ocupar o lugar do nome, na função de substitutos, e que ainda podem indicar a pessoa do discurso, perpassam e permanecem no imaginário conceitual de quem tenha estudado uma língua. Serão essas as funções dos pronomes? Qual seria a sua verdadeira natureza na linguagem? Teriam algum significado próprio ou seriam apenas substitutos? Será que realmente integram uma classe secundária na linguagem? Essas são as questões motivadoras deste trabalho, que busca refletir sobre a visão do pronome, especificamente os pessoais, em alguns pensadores como Ferdinand Saussure (1857-1913), Roman Jakobson (1896-1982), Émile Benveniste (1902-1976) e Andrés Bello (1781-1865).

\section{A visão estruturalista saussuriana do pronome}

Até onde sabemos, o suiço Ferdinand Saussure não fez um estudo específico do pronome. Reconhecido como o "pai da Linguística", na obra póstuma Curso de Linguística Geral (CLG), lançada em 1916 e organizada por dois de seus discípulos, a partir de anotações de cursos ministrados em Genebra, ele confere à Linguística um caráter de cientificidade, definindo seu objeto de estudo, a língua, e seu método, o estruturalismo. Por muito tempo, a comunidade de conhecimento dessa nova área tomou essa obra como referência para os estudos. Mais tarde, soube da existência de outros textos, os manuscritos do próprio autor, que vieram a integrar a obra Escritos de Linguística Geral (ELG, 2002). Isso causou uma reviravolta nos estudos da linguagem, provocando controvérsias, críticas, releituras, reavaliações, convergências e divergências no sentido de atribuir mais ou menos credibilidade, autenticidade a cada uma das obras e interpretação da teoria. Para conhecer o entendimento do pronome por Saussure, consideramos as ideias apresentadas no CLG (1916).

Nessa obra, Saussure apresentou a dicotomia língua/fala e se propôs a trabalhar com a língua, deixando a fala à margem. Definiu a língua como sendo um "acervo linguístico", uma "instituição social" e uma "realidade sistemática e funcional". Ela é homogênea, social, sistemática, formal, unidade, produto, "a língua é um sistema de signos que exprimem ideias [...]" (SAUSSURE, 2016, p. 47). Essa definição de língua excluiu o referente. 0 
estudioso genebrino tomou como objeto de estudo 3 o produto/instrumento da atividade linguística, ou seja, a língua, que é composta por signos arbitrários.

Os signos têm duas partes - o significante, entendido como a imagem acústica, perceptível, e o significado, o conceito, inteligível - que se relacionam imotivadamente. Ou seja, que entre o som e a ideia, entre a representação no mundo real e a imagem acústica, não existe relação natural. Há uma convenção compreendida e garantida pela comunidade linguística. O valor de um signo da língua resulta da relação de oposição com outro signo, ou seja, seu valor está em ser o que outro signo não é dentro do sistema.

Esse entendimento de signo (que se estende ao entendimento do pronome) separao do mundo real e advém da concepção estruturalista de estudo da língua, considerada na sua imanência. Essa visão contempla um estudo que se interessa pelo sistema, pelo código, pela forma, pelo interior, pelo semiótico. Dosse (1994, p. 70), ao comentar a opção de Saussure, afirmou: "Ele encerra a sua linguística num estudo restritivo do código, separada de suas condições de aparecimento e de sua significação."

O pronome então seria um signo arbitrário cujo valor é o que outros signos não são. Quando alguém diz "eu" (yo, Ich, l), o que existe é o significante - a imagem acústica, a tradução psíquica de uma ideia - e o significado - o conceito evocado por esse som. Então, na visão saussuriana do signo, não entra, como já dissemos, o referente do pronome. Desse modo, ao ser estudado, não são considerados quem enunciou aquele "eu", nem a situação que o fez para a constituição do sentido. Em outras palavras, deve ser observado como um elemento (signo) do sistema da língua.

\section{O pronome em Jakobson}

Na obra de Jakobson, conhecemos um trabalho específico sobre os pronomes, em um texto sobre os articuladores ou shifters ${ }^{4}$, intitulado Os articuladores, as categorias verbais e o verbo russo (1957), em que tratou da pessoa e é, a partir desse estudo, que podemos conhecer e apreender a sua ideia do pronome.

\footnotetext{
3 Definir como objeto da linguística a língua foi uma escolha necessária, uma vez que o objetivo de Saussure era torná-la uma ciência. Para tal, é fundamental, um objeto que seja possivel de ser apreendido, que seja tangível. A língua, portanto, enquanto sistema fechado possui esses requisitos, já a fala não, uma vez que é individual, heterogênea, não-sistemática.

4 Os articuladores em Benveniste são denominados dêiticos.
} 
É necessário termos em mente que Jakobson, em seus trabalhos sobre as funções da linguagem ${ }^{5}$, que integram a sua teoria da comunicação, os articuladores e as afasias, difundiu uma visão de língua, fala, linguagem diferenciada da saussuriana e da corrente estrutural. Conforme Flores (2001, p. 18, grifo do autor):

Jakobson pode ser considerado um dos primeiros linguistas a pensar sobre as questões da enunciação porque sua teoria das funções da linguagem e seu trabalho sobre os shifters são algumas das primeiras sistematizações que se tem em linguística sobre o lugar do sujeito na linguagem.

Assim, aspectos de um novo pensamento sobre a linguagem e uma atualização da postura de análise linguística, filha do estruturalismo, surgiram nos trabalhos de Jakobsona enunciação, que se apresentará também em Benveniste de forma mais desenvolvida.

No texto já referido anteriormente, Jakobson fez um estudo propriamente enunciativo da linguagem. Esse texto foi estruturado em duas partes, sendo que a primeira tratou dos quatro tipos de relações existentes entre o código e a mensagem ${ }^{6}$; a segunda parte classificou as categorias verbais a partir de certas distinções. Para este artigo, importa a primeira parte, mais especificamente as passagens em que Jakobson tratou dos pronomes, chegando numa noção mais ampla - a dêixis.

Jakobson (1957) propôs que a mensagem e o código poderiam servir como suportes para a comunicação, funcionando de maneira "desdobrada"7 ou como objetos de referência ou como objetos de utilização. Dessa constatação nascem as estruturas duplas, que são polissêmicas. O que interessa para entender a questão dos pronomes é o que Jakobson denominou "encobrimento parcial" em que o código possui uma classe de unidades gramaticais - os "articuladores" - que só ganham sentido se estiverem inseridos num contexto, referidos à mensagem. Essa visão também é defendida por Benveniste, como poderemos ver na sequência. Para justificar essa proposição, Jakobson recorreu à noção

\footnotetext{
5 Jakobson não foi o primeiro a se dedicar às funções da linguagem. Bühler já as havia estudado, estabelecendo três funções - a representativa, a apelativa e a expressiva. Jakobson as renomeia e ainda propõe mais três: a metalingüística, a poética e a fática.

${ }^{6} \mathrm{O}$ par Código/mensagem pode ser associado, respectivamente, à língua/fala na corrente saussuriana.

7 Podem configurar-se, segundo o autor, de 4 formas: a mensagem pode remeter ao código (M/C) é o caso da sinonímia e da tradução; mensagem pode remeter a outra mensagem (M/M) é o caso do discurso citado; código pode remeter ao código $(C / C)$ é o caso dos nomes próprios e, por último, o código pode remeter à mensagem (C/M), o caso dos articuladores (e também dos pronomes). Às duas primeiras situações, Jakobson chama circularidade e às segundas, encobrimento parcial.
} 
tridimensional do signo linguístico, proposta por Peirce. Para este autor, os signos podem ser enquadrados como símbolos, índex (índices) ou como ícones ${ }^{8}$.

Segundo Jakobson, os articuladores combinam as funções de índice e de símbolo porque podem ser associados a algo e apontar para outra coisa, e isso é que define seu caráter polissêmico. O pronome pessoal "eu" foi citado como um evidente exemplo disso. $\mathrm{O}$ "eu" designa quem o enuncia e também pode apontar, de acordo com um tratado convencional, a outras formas, em outros códigos como "Yo, Ich, Io, I". Funcionando assim, Jakobson (1957) defendeu que "eu" é um símbolo", ou seja, ele representa, simboliza e conceitua a primeira pessoa. Mas, fora disso, o signo "eu" não pode representar o seu sujeito se não estiver "em uma relação existencial" com esse objeto: a palavra "eu", que designa o enunciador, está em uma relação existencial com a enunciação funcionando, portanto, como um índex", ou seja, é um sinal que mostra, indica quem enuncia.

Resumindo, podemos dizer que os pronomes pessoais, na mensagem, funcionam como índice, por meio de um processo metonímico, e, no código, como símbolo, através de um processo metafórico9 ${ }^{9}$. Também é preciso considerar que sua significação é determinada conforme a ocasião em que surgem, para que direção apontam e a quem se referem em um texto. Na verdade, a partir desse estudo, esses pronomes, assim como outros dêiticos, mostram-se como estruturas complexas, que funcionam de forma polissêmica, isto é, têm duplo sentido ou dupla função. Eles são símbolos-índices, em que código e mensagem se

\footnotetext{
${ }^{8}$ Peirce entende que o índice designa uma relação causal entre um fato linguístico e o objeto significado. Ou seja, a relação estabelecida é de contiguidade com a realidade exterior. Fornece como o próprio nome sugere uma indicação, permitindo o raciocínio inferencial. O exemplo dado é o da fumaça. "Se há fumaça, há fogo". Aqui é possível ver a relação causa-efeito, bem como a questão da indicação e da inferência que é preciso fazer para entender. Na linguística, tudo o que depende da dêixis é um índice. O símbolo é visto por Peirce como aquele que procede de uma convenção, ou seja, refere-se a alguma coisa, mas perante força de uma lei. Assim, opera por contiguidade que já foi instituída e apreendida entre o significante e o significado. É por uma regra já aceita que a "balança" representa ou simboliza a justiça. Os ícones são aqueles que operam pela relação de semelhança entre significante e significado, ou seja, a representação e o que é de fato representado. Assim, o ícone seria aquele que reproduz fazendo uma transferência. Um exemplo disso seria uma foto. Há autores, e um deles é Roman Jakobson, que acreditam que o signo linguístico é constituído pelo símbolo e pelo índice (sinal), ou seja, ele pode mostrar e representar. Como exemplo, sugere os pronomes que mostram em vez de representar como fazem os nomes.

9 É pelo processo metafórico que, no código (langue), os pronomes podem funcionar como símbolos. Ou seja, podem ser associados à outra forma em outros códigos e também porque o nome (locutor) pode ser designado pelo nome de um objeto semelhante (o pronome). Pelos fatores substituição e associação que existem nesse processo, poderia corresponder ao eixo paradigmático (Saussure). Os pronomes podem funcionar como índices pelo processo metonímico, na mensagem (parole). Isso quer dizer que um objeto (nome) é designado pelo nome de um objeto semelhante que está associado na experiência, no uso. Assim, só tem razão de ser e funcionar como tal no contexto utilizado, e essa é uma característica do processo metonímico. Quer dizer, sempre há entre o objeto designado e aquele que designa uma relação de dependência. O processo metonímico poderia corresponder ao sintagmático (Saussure).
} 
entrelaçam. Benveniste, em seu estudo sobre os pronomes, considerou tais afirmações de Jakobson.

A posição de Jakobson sobre os articuladores (entre eles, os pronomes) demonstrou considerar o código, mas também a mensagem e, com isso, o sujeito, o contexto e o sentido. Inclusive, a corrente enunciativa propôs como seu objeto de estudo o ato de produção do enunciado e não o enunciado pronto (produto), dando sinais de uma mudança, em que elementos abandonados passam a interessar.

Para Jakobson (1957), os articuladores, os pronomes pessoais, por exemplo, têm significação: "assim, "eu" designa o destinador (e "tu" o destinatário) da mensagem à qual pertence". Isso mostra que o autor não via os pronomes apenas como substitutos dos nomes ou indicadores das pessoas do discurso, mas como signos que têm sentido particular, ampliando a percepção trazida pelas gramáticas normativas e dicionários de língua. Já dissemos que Benveniste compartilha com Jakobson essa caracterização dos pronomes, postura que também se encontra em dicionários de linguística. Para exemplificar, trazemos a noção de pronome, que está dentro do verbete "dêixis" do Dicionário de Linguística e Gramática: referente à língua portuguesa de Câmara Junior (2002, p. 90, grifos do autor):

Dêixis - faculdade que tem a linguagem de designar mostrando, em vez de conceituar. A designação dêitica, ou mostrativa, figura assim ao lado da designação simbólica ou conceptual em qualquer sistema lingüístico. Podemos dizer que o SIGNO lingüístico apresenta-se em dois tipos - o SíMBOLO, em que um conjunto sônico representa ou simboliza, e o SINAL, em que o conjunto sônico indica ou mostra (...). O pronome é justamente o vocabulário que se refere aos seres por dêixis em vez de o fazer por simbolização como os nomes. Essa dêixis se baseia no esquema lingüístico das três pessoas gramaticais que norteia o discurso: a que fala, a que ouve e todos os mais situados fora do eixo falante-ouvinte.

\section{A natureza e as características do pronome em Benveniste}

Benveniste, na sua teoria da enunciação, fez um estudo dos pronomes de forma detalhada, uma vez que são fundamentais para a subjetividade na linguagem, cerne de sua teoria. Em dois de seus textos, tratou dos pronomes: Estrutura das relações de pessoa no verbo (1946) e A natureza dos pronomes (1956), mostrando como essa categoria é a primeira a instaurar e representar a subjetividade na linguagem. Defendeu que não há língua que não 
tenha, em seu sistema, a classe pronominal e, por consequência, que se conceba sem as marcas de sujeito na sua realização.

No texto de 1946, Benveniste, ao propor a categoria de pessoa, definiu as pessoas do discurso. Considerou eu/tu como as autênticas pessoas do discurso em oposição a ele - a não-pessoa. A partir disso, estabeleceu duas oposições básicas resultantes na correlação de personalidade, que opõe pessoa (participantes do diálogo) à não-pessoa (exterior ao diálogo) e na correlação de subjetividade, na qual se opõem o eu e o não-eu (tu), que juntos se contrapõem a não - pessoa (ele $)^{10}$. Também nesse texto, inovou ao dizer que os pronomes pessoais no plural não significam apenas pluralização. É o caso de "nós" e "vós". Somente a forma "eles"- por não ter marca de pessoa- indica verdadeiro plural. Ainda, definiu o "nós" como inclusivo (união de um eu, pessoa subjetiva, a um tu/vós, pessoa não subjetiva) e exclusivo (eu, pessoa + ele(s), não pessoa). Não podem significar plural porque não demonstram a repetição da mesma pessoa. No caso do "nós" não há soma de diferentes pessoas e nem repetição de "eus" e no caso do "vós", no sentido coletivo ou cortesia, não há soma de vários "tus".

O primeiro fato a que Benveniste chamou atenção é que os pronomes não deveriam mais ser considerados como uma "classe unitária", quando se referem à forma e à função. Diferenciou o aspecto formal dos pronomes, pertencente à parte sintática da língua, do funcional, considerado característico da instância do discurso, ou seja, da enunciação. Quer dizer, os pronomes se configuram numa classe da língua que opera no formal, sintático, e no funcional, pragmático. Sendo assim, os pronomes deveriam ser entendidos também como fatos de linguagem, pertencentes à mensagem (fala), às categorias do discurso (semântico) e não apenas como pertencentes ao código (língua), às categorias da língua (semiótico). Com isso, Benveniste ampliou a visão estruturalista e caminhou na direção de Jakobson. Essa concepção dos pronomes, também como categoria de linguagem, é dada pela posição que nela ocupam.

Benveniste constatou que os signos nominal e pronominal são diferentes. Um nome de um objeto, por exemplo, "casa" possui um conceito ao qual todas as aplicações individuais podem ser remetidas. Já um pronome como "eu" não tem um conceito ao qual

\footnotetext{
${ }^{10} E$ É importante lembrar que essa concepção de pessoa e não-pessoa não é a única na Linguística. Cervoni (1989), por exemplo, é um dos linguistas que considera a terceira pessoa "ele" como uma pessoa verdadeira, inclusive afirmando que ela é fundamental, pois é suporte necessário a toda enunciação.
} 
possam ser reportados todos os "eus" que o assumem na enunciação. Isso acontece porque o signo "eu" (assim como "tu" e outros dêiticos) não denomina nenhuma entidade específica, mas refere-se à fala individual onde se coloca, marcando o lugar de quem enuncia, do locutor.

Assim sendo, Benveniste propôs outra dicotomia a partir dessa: nível pragmático e nível sintático. O linguista caracterizou o nível pragmático como sendo lugar do par eu-tu, e isso se justifica porque é no discurso, no uso da língua, que se constituem e se tornam cada vez únicos. No nível sintático, está a não - pessoa "ele", já que não depende da situação do discurso para existir.

O autor caracterizou os pronomes que têm marca de pessoa (eu/tu) como sendo categorias de discurso, como formas vazias, pertencentes ao nível pragmático, que só ganham plenitude e sentido quando assumidos por um falante, na instância de discurso. Essa tomada é sempre única, móvel e inversível, representando a (inter)subjetividade na linguagem. O pronome de terceira pessoa, ao contrário, é um signo pleno, uma categoria da língua, pertencente ao nível sintático, que tem referência objetiva e o seu valor independe da instância da enunciação, declarando, portanto, a objetividade na linguagem. Essa postura benvenistiana sobre o pronome e os demais dêiticos ${ }^{11}$ é consequência do seu entendimento de signo.

Benveniste considerou tal como Saussure as partes do signo, mas questionou a relação entre elas. Para o linguista francês, o que une significante e significado é a relação de necessidade e não de arbitrariedade. Para comprovar que o elo entre os dois elementos do signo é definido pela necessidade, Benveniste se apoiou no conceito de oposição já mencionado antes por Saussure e pelos estruturalistas. O arbitrário estaria no significado e sua relação com a realidade, ou seja, o domínio da arbitrariedade seria externo à compreensão linguística porque não faria parte da constituição interna do signo. Segundo Benveniste (1995, p.56), "O que é arbitrário é que um signo, mas não outro, se aplica a determinado elemento da realidade, mas não a outro".

\footnotetext{
${ }^{11}$ A dêixis, para Benveniste, comporta elementos que se referem a três ordens: pessoa, tempo e espaço. Tem como elemento central a categoria de pessoa (pronomes), sendo os demonstrativos, advérbios e verbos (categorias de tempo e lugar) dependentes da de pessoa. Os dêiticos de tempo e espaço assumem as mesmas características da pessoa e juntos desempenham um papel importante na linguística enunciativa: dão roupagem para o sujeito se manifestar na linguagem.
} 
Benveniste propôs, assim, uma linguística das formas e uma lingüística da enunciação no seu artigo "O aparelho formal da enunciação" (1970). A primeira trata de descrever as regras sintáticas que regem essas formas na língua, considerando-a como objeto estruturado. A linguística da enunciação não ignora a descrição da linguística das formas, mas inclui como objeto de estudo a enunciação e, consequentemente, os elementos envolvidos nesse processo, ou seja, a dêixis, que acreditamos ser um elemento constitutivo fundamental nessa teoria. Segundo Lahud (1979, p.97): "Pois a verdade é que um novo palco onde a noção de dêixis desempenha papel relevante - senão principal - é constituído pela assim chamada "linguística da enunciação"", esta em que a língua permanece a mesma, mas a sua significação é única, dada por cada ato enunciativo. Para Benveniste, o sujeito (fala) provoca a atualização do sistema.

Para Benveniste (1989, p. 81), a situação do emprego das formas e da língua são diferentes porque acredita que "são, em realidade, dois mundos diferentes, e pode ser útil insistir nesta diferença, a qual implica uma outra maneira de ver as mesmas coisas, uma outra maneira de as descrever e de as interpretar". Os pronomes pessoais integrariam essas duas linguísticas, só podendo atribuir-lhes sentido no momento da enunciação.

\section{O pronome para Andrés Bello ${ }^{12}$}

Para dar a conhecer a visão do pronome de Andrés Bello ${ }^{13}$ e refletir sobre ela, tomamos seu texto principal, a Gramática de la lengua castellana destinada al uso de los americanos, publicado em 1847, no Chile, já que o autor não fez um estudo específico sobre o pronome em uma obra. Bello não foi um linguista nem um gramático no sentido que conhecemos hoje, mas, talvez, um filólogo, um entusiasmado estudioso da língua. Nesse

\footnotetext{
${ }_{12}$ Andrés de Jesús María José Bello López nasceu em Caracas, Venezuela, em 1781 e faleceu em Santiago, Chile, em 1865. Pertenceu a uma família culta, teve acesso à educação clássica e religiosa, formando-se a partir dos valores da llustração. Bello sabia latim, francês e inglês e era leitor e estudioso de textos europeus. Formou-se em Artes, na Universidade de Caracas. Exerceu várias funções durante sua vida e foi um polígrafo. Entre suas funções, destacaram-se: funcionário no governo em Caracas, professor (inclusive de Simon Bolívar), diplomata em Londres, durante 19 anos, senador no Chile, um dos fundadores e reitor da Universidad de Chile. Foi um polígrafo, atuando em diferentes áreas do saber: literatura, língua, filosofia, direito, jornalismo. Escreveu e publicou muitas obras, mas as duas de maior destaque são o Código Civil de la República de Chile (1856) e a Gramática dela lengua castellana destinada al uso de los americanos (1847). ${ }_{13}$ Justificamos trazer a abordagem de Bello junto a dos demais autores neste trabalho porque sua visão do pronome é muito interessante não somente por estar dentro de uma gramática, mas também por ser adiantada para a época em que viveu.
} 
livro, que sintetiza e traduz seu pensamento gramatical, o pronome é tratado, mas não da forma como imaginamos. Quer dizer, por ser uma gramática, nosso olhar, construído a partir de uma tradição, se direcionaria para o índice, buscando pelo capítulo em que contempla essa classe de palavras e ainda em capítulos iniciais da obra em que apresenta a sua divisão das classes de palavras.

Esse exame já nos causa um estranhamento porque não encontramos o pronome da maneira esperada. Bello, trouxe no capítulo 2, "Clasificación de las palabras por sus oficios", o seguinte: verbo, substantivo, adjetivo, adverbio, preposição, conjunção e interjeição. Segundo ele, essas seriam as sete classes de palavras que a língua castelhana teria. Ou seja, não reconheceu o pronome, o artigo e o numeral como classes. Além disso, tal ordem de apresentação, provavelmente, seja a ordem de importância de função que o autor dava a elas na língua. Diante disso, qual foi o lugar destinado por Bello às palavras que não tinham estatuto de classe? Bello as colocou no interior da classe dos substantivos, que passou a chamar de "nombres".

Apresentou cada classe de um modo geral e depois desenvolveu os temas nos capítulos da gramática. Ao falar do verbo, nos deparamos com a noção de pessoa. Bello atrelou ao verbo essa noção, explicitando o que pensava sobre ela, conforme mostra a transcrição do fragmento:

La palabra PERSONA, que comúnmente, y aun en la gramática, suele significar lo que tiene vida y razón, lleva en el lenguaje gramatical otro significado más, denotando las tres diferencias de primera, segunda y tercera, y comprendiendo en este sentido a los brutos y los seres inanimados no menos que las verdaderas personas". (BELLO, 1847, p.42, grifo do autor) ${ }^{14}$

No caso dos pronomes, foco deste trabalho, há um capítulo da gramática em que Bello tratou deles, a saber: Capítulo XIII - De los pronombres. Nesse lugar, é onde está a visão do pronome de Bello. Assim lemos: "Llamamos pronombres los nombres que significan primera, segunda o tercera persona, ya expresen esta sola idea, y la asocien con otra". (BELLO,

\footnotetext{
${ }^{14}$ A palavra PESSOA, que comumente, e ainda, na gramática, costuma significar aquilo que tem vida e razão, leva na linguagem gramatical outro significado, denotando as três diferenças de primeira, segunda e terceira, e compreendendo neste sentido aos brutos e aos seres inanimados não menos que as verdadeiras pessoas". (tradução nossa)
} 
1847, p. 57) $)^{15} \mathrm{Na}$ sequência, apresentou uma subdivisão em pronomes pessoais, possessivos e demonstrativos. Dentre eles, nos interessa os pronomes pessoais. Essa redivisão se deu de acordo com sua função na língua em aqueles que exerceriam a posição de sujeito, no caso nominativo (yo, nosotros/as, tú, vosotros/as) ${ }^{16}$ e os que ocupariam a função de complemento, casos acusativo/dativo (me, nos, te, vos) ou de término (mí, nosotros/as, tí, vosotros/as), referentes à primeira, segunda e terceira pessoa do discurso. Seriam então quatro casos.

Observemos pela descrição de Bello que a terceira pessoa (él/ella, ellos/ellas) não aparece. No seguinte fragmento, "La misma indeterminación de persona se encuentra aun en los adjetivos él y aquel, que se tienen por de la tercera" (BELLO, 1847, p. 93) ${ }^{17}$, aproxima o pronome "él" ao pronome demonstrativo "aquel" porque teriam a mesma característica. Isso vai confirmando a exclusão dos pronomes de terceira pessoa nos exemplos apontados na gramática, pelo fato de que via entre a primeira e a segunda estatutos diferentes da terceira, e isso impediria apresentá-las todas dentro da mesma categoria.

Os pronomes pessoais " $y o$ " e "tú", de primeira e segundas pessoas, respectivamente, indicariam, por sua natureza, as pessoas do momento da enunciação, enquanto que "él" e derivados, de terceira pessoa, por seu caráter de indeterminação se aproximariam mais dos pronomes demonstrativos do que dos pronomes pessoais propriamente. Ou seja, "él" necessitaria ligar-se a outros elementos, outras palavras para poder adquirir um significado que remetesse à pessoalidade. Não traz intrinsecamente esse sentido, diferentemente de "yo" e "tú".

Bello não desenvolveu mais essa ideia quiçá porque não era o texto propício para dar explicações ou fazer divagações teóricas, era uma gramática. No entanto, deixou entrever o paralelo: pessoas verdadeiras (yo, tú e seus plurais) e pseudo-pessoa (él e variantes), sendo as primeiras, autônomas no discurso, uma vez que expressam, por sua natureza, um significado - o de pessoa da fala, e a segunda, dependente de outros elementos para significar a mesma coisa.

\footnotetext{
15 "Chamamos pronomes os nomes que significam primeira, segunda ou terceira pessoa, já expressem somente esta ideia, e a associem com outra". (tradução nossa)

${ }^{16}$ Bello também tratou do pronome "vos", um uso corrente no Chile da época da escrita da gramática (e de outras nações latino-americanas), como uma alternativa ao pronome "tú". Censurou seu emprego, afirmando ser uma vulgaridade que deveria ser evitada.

17 "A mesma indeterminação de pessoa se encontra ainda nos adjetivos ele y aquele, que se toma como de terceira." (tradução nossa)
} 


\section{Considerações Finais}

A partir das perspectivas estudadas neste texto, é possível observar que há diferenças no entendimento do pronome. Para o pai da Linguística Moderna, o pronome pessoal é um signo linguístico arbitrário como outro, cujo sentido não é determinado pela referência no mundo real. Já, numa postura enunciativa, como vemos em Jakobson e Benveniste, o pronome pessoal (e os dêiticos) é visto como um signo diferente do nome, necessitando da referência para ter valor. O sentido é dado pela referência. São unidades duplas que podem remeter à língua, e nessa situação são vazias de sentido, e à enunciação (instância de discurso), nesse caso, plenas de sentido. Há uma ampliação do que o mestre Saussure fez alusão, a referência, o sujeito, o contexto.

Além disso, na postura enunciativa benvenistiana, os pronomes pessoais, ao lado dos demonstrativos, verbos, advérbios, ou seja, os dêiticos, têm uma função muito importante porque seriam indicadores da subjetividade na linguagem. Quer dizer, o sujeito se utiliza dessa classe especial de signos (e não só dela) para revelar-se na linguagem. Sendo assim, são elementos fundamentais para o cerne da teoria da enunciação que propõe Benveniste - a subjetividade. Portanto, o pronome pessoal (e outros dêiticos) são signos diferentes dos nomes uma vez que atuam em dois níveis sendo que importa muito a referência ao discurso.

A perspectiva de Bello sobre o pronome, mostrada na gramática, difere da gramática da RAE, em dois aspectos: primeiro, não compreendeu o pronome como uma classe gramatical, inserindo-o na classe dos substantivos (nomes); e segundo, reconheceu que "yo, tú, nosotros/as, vosostros/as", as pessoas da fala, têm diferente estatuto de "él/ella(s)", "a não-pessoa". Para chegar a esse entendimento, provavelmente, tenha feito uma análise dessas categorias para além da frase, considerando o ato da palavra, o momento da enunciação. Essa última ideia o aproxima do pensamento de Benveniste. $O$ curioso é que um século os separa. Nesse sentido, podemos enxergar no entendimento de Bello sobre a categoria de pessoa e o pronome um vislumbre de um intelectual sensível e aberto ao que está além da frase, da forma, o que o fez reconhecer que a singularidade da primeira e segunda pessoas não é a mesma da terceira.

Diante dessas visões sobre os pronomes na linguagem, vimos que há entendimentos diferentes, mas temos que enxergá-los como um elemento da língua em funcionamento, 
pois só assim tem realmente sentido. Por essa postura, os pronomes pessoais não teriam apenas a função de substituir ou de representar um nome ou as pessoas do discurso, mas seriam também categorias duplas que atuariam na língua e no discurso e que expressariam, inclusive, o sujeito na linguagem, função do pronome pessoal que certas gramáticas da língua e dicionários têm ocultado.

\section{Referências}

BELLO, A. Gramática de la lengua castellana destinada al uso de los americanos. Santiago de Chile: Imprenta del progreso, 1847. Disponível em: Biblioteca Nacional Digital do Chile <http://www.memoriachilena.cl/archivos2/pdfs/MCo014882.pdf> Acesso em: 23 mar. 2018.

BENVENISTE, E. A natureza do signo linguístico. In: Problemas de Linguística Geral I. Tradução de Maria da Glória Novak e Maria Luisa Neri. 4ed. Campinas/SP: Pontes, 1995. p.53-59.

Estrutura das relações de pessoa no verbo. In: Problemas de Linguística Geral I. Tradução de Maria da Glória Novak e Maria Luisa Neri. 4ed. Campinas/SP: Pontes, 1995. p. 247-259

A natureza dos pronomes. In: Problemas de Linguística Geral I. Tradução de Maria da Glória Novak e Maria Luisa Neri. 4ed. Campinas/SP: Pontes, 1995. p. 277-283.

. Da subjetividade na linguagem. In: Problemas de Linguística Geral I. Tradução de Maria da Glória Novak e Maria Luisa Neri. 4ed. Campinas/SP: Pontes, 1995. p. 284-293.

. O aparelho formal da enunciação. In: Problemas de Linguística Geral II. Tradução de Eduardo Guimarães et al. Campinas/SP: Pontes, 1989.

CÂMARA JUNIOR, J. M. Dicionário de Linguística e Gramática: referente à língua portuguesa. 13.ed. Petrópolis: Vozes, 2002.

CERVONI, J. A enunciação. São Paulo: Ática, 1989.

DOSSE, F. História do estruturalismo. O canto do cisne, de 1967 a nossos dias. v. 2. São Paulo: Editora Ensaio, 1994.

FLORES, V.N. Princípios para a definição do objeto da linguística da enunciação: Uma introdução (primeira parte). In: Letras de hoje. Porto Alegre. v. 36, nº 4. 2001, p. 7-65.

JAKOBSON, R. Os articuladores, as categorias verbais e o verbo russo, 1957. (versão mimeografada) 
LAHUD, M. A propósito da noção de dêixis. São Paulo: Ática, 1979.

REAL ACADEMIA ESPAÑOLA. Diccionario de la lengua española. Madrid: Espasa Calpe S.A, 2018. Disponível em: < https://dle.rae.es/?w=diccionario> Acesso em: 7 jun. 2019.

Gramática de la Lengua Castellana compuesta por la Real Academia Española. Madrid: D. Joachin de Ibarra, 1771. Disponível em: <http://www.cervantesvirtual.com/obravisor/gramatica-de-la-lengua-castellana--4/html/ff8a76b2-82b1-11df-acc7002185ce6064_2.html> Acesso em: 7 jun. 2019.

SAUSSURE, F. de. (1916) Curso de Linguística Geral. Tradução de Antônio Chelini, José Paulo Paes, Isidoro Blikstein. 28 ed. São Paulo: Cultrix, 2016.

Escritos de linguística geral. Tradução Carlos Augusto Leuba Salum, Ana Lúcia Franco. São Paulo: Cultrix, 2002.

'Docente do Departamento de Ensino do Colégio Politécnico da Universidade Federal de Santa Maria e Doutoranda em Letras - Estudos Linguísticos na mesma instituição, sob a orientação da Profa. Dra. Eliana Rosa Sturza.

E-mail: kcgbr@yahoo.com.br

\author{
RECEBIDO EM 10/06/2019 \\ ACEITO EM 21/08/2019
}

